\title{
Enhancement of photoinscription process in fused silica by thermal treatment (Withdrawal Notice)
}

\section{Badrinath Vadakkapattu C., Madhura Somayaji}

Badrinath Vadakkapattu C., Madhura R. Somayaji, "Enhancement of photoinscription process in fused silica by thermal treatment (Withdrawal Notice)," Proc. SPIE 10755, Photonic Fiber and Crystal Devices: Advances in Materials and Innovations in Device Applications XII, 107550X (4 September 2018); doi: 10.1117/12.2322513

Event: SPIE Optical Engineering + Applications, 2018, San Diego, California, United States 


\section{Enhancement of photoinscription process in fused silica by thermal treatment (Withdrawal Notice)}

Badrinath Vadakkapattu C., ${ }^{1}$ Madhura R. Somayaji2

'Karlsruhe School of Optics and Photonics (Germany)

2Lab. Hubert Curien, Univ. of Lyon, Univ. Jean Monnet (France)

Proceedings Volume 10755, Photonic Fiber and Crystal Devices: Advances in Materials and Innovations in Device Applications XIl; 107550X (2018) https://doi.org/10.1117/12.2322513

Event: SPIE Optical Engineering + Applications, 2018, San Diego, California, United States

Online Publication Date: 4 September 2018

Withdrawn from Publication: 22 June 2020

Publisher's Note: This paper, originally published on 4 September 2018, was withdrawn per author request. 